\title{
Time to "go large" on biofilm research: advantages of an omics approach
}

\author{
Nuno F. Azevedo · Susana P. Lopes • \\ Charles W. Keevil · Maria O. Pereira • \\ Maria J. Vieira
}

Received: 5 September 2008/Revised: 2 December 2008/Accepted: 5 December 2008/Published online: 31 December 2008

(C) Springer Science+Business Media B.V. 2008

\begin{abstract}
In nature, the biofilm mode of life is of great importance in the cell cycle for many microorganisms. Perhaps because of biofilm complexity and variability, the characterization of a given microbial system, in terms of biofilm formation potential, structure and associated physiological activity, in a large-scale, standardized and systematic manner has been hindered by the absence of high-throughput methods. This outlook is now starting to change as new methods involving the utilization of microtiter-plates and automated spectrophotometry and microscopy systems are being developed to perform large-scale testing of microbial biofilms. Here, we evaluate if the time is ripe to start an integrated omics approach, i.e., the generation and interrogation of large datasets, to biofilms- "biofomics". This omics approach would bring much needed insight into how biofilm formation ability is affected by a number of environmental, physiological and mutational factors and how these factors interplay between themselves in a standardized
\end{abstract}

N. F. Azevedo $(\square) \cdot$ S. P. Lopes · M. O. Pereira · M. J. Vieira

IBB, Institute for Biotechnology and Bioengineering, Centre of Biological Engineering, Universidade do Minho, Campus de Gualtar, Braga 4710-057, Portugal e-mail: nunoazevedo@deb.uminho.pt

N. F. Azevedo · C. W. Keevil

Environmental Healthcare Unit, Microbiology Group,

School of Biological Sciences, University of

Southampton, Bassett Crescent East,

Southampton SO16 7PX, UK manner. This could then lead to the creation of a database where biofilm signatures are identified and interrogated. Nevertheless, and before embarking on such an enterprise, the selection of a versatile, robust, high-throughput biofilm growing device and of appropriate methods for biofilm analysis will have to be performed. Whether such device and analytical methods are already available, particularly for complex heterotrophic biofilms is, however, very debatable.

Keywords Biofomics · High-throughput . Systems biology · Biofilms · Database

\section{Applied and basic biofilm studies}

The importance of biofilm formation in the cell cycle of many bacteria has now been widely recognized (Kolter 2005; Kolter and Greenberg 2006). In nature, these structures are usually composed of multispecies associations that interact and communicate using complex intra- or inter-species signaling pathways (Parsek and Greenberg 2005; Camilli and Bassler 2006). It is widely acknowledged that biofilm formation is affected by the species or heterotrophic consortium that is present and by the environmental conditions involved.

Biofilms affect very diverse areas of importance to human development, such as clinical, industrial and environmental microbiology. It comes therefore as no surprise that many in situ biofilm studies look at very 
complex systems, usually involving uncharacterized consortia of microorganisms and undefined liquid media (e.g. Battin et al. 2003; Wilmes et al. 2008). Even though the collection of information in these cases is necessary to tackle particular issues-for instance to determine community structures or assess biofilm impact in certain ecosystems (Battin et al. 2003; Ram et al. 2005; Tringe et al. 2005; Wilmes et al. 2008) — the understanding of the underlying adhesion phenomena and biofilm formation mechanisms is overshadowed by a number of factors. Examples of such factors include the lack of basic knowledge in the adhesion ability by the different microorganisms involved and how is biofilm development affected by the large spectrum of environmental conditions that are known to influence biofilm structure, composition and function.

In vitro biofilm experiments in tightly controlled conditions, which can be traced back to the mid 80s (e.g. Bakke et al. 1984; Nickel et al. 1985), have arisen to fill in this information gap, together with the development of several biofilm-forming devices (Table 1). In vitro studies have, for instance, allowed a more in-depth characterization of the effect of quorum-sensing molecules after they have been found to be present in naturally-occurring biofilms (McLean et al. 1997; Hardie and Heurlier 2008). Even though in vitro studies assess the influence of a pre-determined set of environmental, physiological or mutational conditions in biofilm formation, it is still not straightforward to compare the relative importance of these conditions and/or to study possible inter-relationships between them. This occurs mainly because most biofilm-forming devices are not sufficiently versatile and/or easy to operate in order to generate large amounts of reproducible data under different conditions (Table 1). Another important reason is that it is very difficult to control all the complex variables that influence biofilm formation, especially when working with a complex species

Table 1 Examples of biofilm-forming devices together with their most notorious characteristics and limitations

\begin{tabular}{|c|c|c|c|}
\hline Biofilm device & Main advantages & Main disadvantages & Ref.(s) \\
\hline $\begin{array}{l}\text { Modified robbins } \\
\text { device }\end{array}$ & $\begin{array}{l}\text { Well defined hydrodynamic conditions. } \\
\text { Operation at continuous culture conditions }\end{array}$ & Low throughput & $\begin{array}{l}\text { (Evans and Holmes 1987; } \\
\text { Kharazmi et al. 1999) }\end{array}$ \\
\hline $\begin{array}{l}\text { Two-stage } \\
\text { chemostat }\end{array}$ & $\begin{array}{l}\text { Avoids leakage while working under } \\
\text { continuous culture conditions. Ideal for the } \\
\text { study of biofilm formation by pathogens }\end{array}$ & Low throughput & (Keevil 2001) \\
\hline Flow cell & $\begin{array}{l}\text { The flat surface of the reactor allows direct } \\
\text { microscopy observation without changing } \\
\text { the hydrodynamics of the system }\end{array}$ & Low throughput & (Bragança et al. 2007) \\
\hline $\begin{array}{l}\text { Perfused biofilm } \\
\text { fermentor }\end{array}$ & $\begin{array}{l}\text { Allows growth-rate control of adherent } \\
\text { microbial populations }\end{array}$ & Low throughput & $\begin{array}{l}\text { (Gilbert et al. 1989; Baillie } \\
\text { and Douglas 1998) }\end{array}$ \\
\hline $\begin{array}{l}\text { Constant Depth Film } \\
\text { Fermentors }\end{array}$ & $\begin{array}{l}\text { Generates biofilms of fixed depth. Typically } \\
\text { applied in biofilms relevant to dental health } \\
\text { and contact lenses }\end{array}$ & Low throughput & $\begin{array}{l}\text { (Kinniment et al. 1996; } \\
\text { McBain et al. 2003) }\end{array}$ \\
\hline Microtitre plate & $\begin{array}{l}\text { High-throughput. Also allows insertion of } \\
\text { coupons in each well for direct } \\
\text { microscopy, but in that case the method is } \\
\text { low throughput }\end{array}$ & $\begin{array}{l}\text { Direct observation of wells } \\
\text { under the microscope is } \\
\text { complicated. } \\
\text { Quantification using } \\
\text { automated methods } \\
\text { suffers from lack of } \\
\text { reproducibility }\end{array}$ & $\begin{array}{l}\text { (Stepanovic et al. 2000; } \\
\text { Azevedo et al. 2006a) }\end{array}$ \\
\hline Calgary device & $\begin{array}{l}\text { High-throughput. Allows direct observation } \\
\text { and quantification of biofilms under the } \\
\text { microscope }\end{array}$ & $\begin{array}{l}\text { Introduction of an extra } \\
\text { surface in the microtitre } \\
\text { plate system. Biofilms } \\
\text { formed "upside-down" }\end{array}$ & (Harrison et al. 2005) \\
\hline BioFilm ring test & $\begin{array}{l}\text { High-throughput. Requires very few } \\
\text { manipulations after the initial bacterial } \\
\text { inoculation, ensuring a better } \\
\text { reproducibility than the microtitre plates }\end{array}$ & $\begin{array}{l}\text { Not fully tested nor } \\
\text { automated }\end{array}$ & (Chavant et al. 2007) \\
\hline
\end{tabular}


heterotrophic consortium, and hence obtain reproducible biofilms.

It comes, therefore, as no surprise that one of the major drawbacks in biofilm formation studies is the problematic comparison of results obtained when using different methodologies and biofilm growth systems, particularly between different research groups. Consequently, inter-laboratory comparison of results is usually limited and performed qualitatively rather than quantitatively. This has so far implied that a database, where the biofilm-forming characteristics of a given system containing one or more microorganisms are stored, has not yet been created.

\section{Biofomics: large-scale acquisition of biofilm characteristics}

An omics data set is now used as a generic term to describe genome-scale data sets that are emerging from high-throughput technologies (Joyce and Palsson 2006). The most familiar examples include whole genome sequencing data (genomics), microarray based genome-wide mRNA expression profiles (transcriptomics) and the large-scale study of proteins in organisms (proteomics), but there are dozens of other data sets. Phenomics, for instance, refers to the highthroughput determination of cellular fitness or viability in response to genetic and/or environmental perturbations (Bochner 2003).

Invariably, data gathered from these types of studies end up in online omics databases that can be freely accessible by the scientific community (Feingold et al. 2004; Liolios et al. 2006). These omics websites, generally the result of combined efforts between different institutions, provide information on either components (genomics, proteomics, localizomics), interactions (protein-protein and gene-protein) or functional states (fluxomics, phenomics) of a population of cells (Joyce and Palsson 2006). Omics data sets are now being integrated to provide a more comprehensive picture of microbial behaviour, in the highprofile subject of systems biology (Ge et al. 2003; Joyce and Palsson 2006).

Here, an omics approach to the field of biofilms"biofomics"-is suggested. "Biofomics" would apply to studies reporting the generation of automated, large amounts of data addressing the so important ability of a microorganism to attach to surfaces, inter relate with its neighbors, and create biofilms. Biofomics would therefore provide data to reveal an aspect of the overall behavior of the cell or system, and is thus part of the functional state category, together with fluxomics and phenomics. In a similar way to all other omics disciplines, the collected data would be gathered in a database, in order to be freely available to the scientific community. During the next sections, we will review the state-of-the-art in high-throughput devices for biofilm formation, propose the parameters that might be relevant to assess and control on a "biofomics" approach, discuss the issues that need to be overcome for creating and establishing a "biofomics" database, and explain why such a database is important for the biofilm area of research.

\section{High-throughput devices for biofilm assessment}

Systematic high-throughput testing of biofilms has just now started to arise (Table 1). However, the first attempts were started more than 20 years ago when Christensen et al. (1985) employed a microtiter-plate test to grow and assess biofilms, a study that was followed by the development of a modified microtiterplate test by Stepanovic et al. (2000). In the earlier work, biofilms grown in well plates were stained with Crystal Violet (CV) and quantified directly by optical density (OD). Stepanovic et al. (2000) introduced a step that released the bound CV from the biofilm with a solution of acetic acid, measuring the OD of the liquid instead.

Due to its larger data generation ability when compared to the other available systems at the time, application of colorimetric assays directly in well plates to assess biofilm formation has expanded in the meantime (Pettit et al. 2005; Burmolle et al. 2006). New assays are now able to assess not only biofilm formation as a whole but also quantify microbial numbers or the extracellular biofilm matrix (Peeters et al. 2008). In spite of showing very promising characteristics, experiments performed using 96-well plates and the methods described above are, at times, suffering from lack of reproducibility between different laboratories, possibly due to the washing steps that are researcher-dependent and to the existence of several protocol versions. Moreover, an assessment of biofilm structure by microscopy has been impossible due to the narrow geometry of the well plates. 
In order to address part of these problems, Ceri and colleagues applied a combination of the 96-well microtiter plates and the Calgary Biofilm Device to develop high-throughput susceptibility testing of microorganisms in biofilms (Ceri et al. 1999; Harrison et al. 2005, 2007). This device appears to be more amenable for observation using scanning electron microscopy (SEM), episcopic differential interference contrast (EDIC), microscopy with epifluorescence (EDIC/EF) or confocal laser scanning microscopy (SCLM), and it is hence more practical to perform structure-function analysis of biofilms under multivariate growth and exposure conditions (Keevil 2003; Harrison et al. 2006). Even so, this device introduces an extra surface in the wells (the pegs) where the biofilm is to be formed and analyzed. The influence of forming an "upside-down" biofilm in those pegs and how this biofilm compares to the biofilm formed at the bottom of a well has not, in our opinion, been totally addressed. It does, however, overcome problems of non-specific cell sedimentation which may not accurately relate to biofilms.

Another high-throughput biofilm-forming device based on well plates, the BioFilm Ring Test, has also been recently presented by Chavant et al. (2007). The method is based on the immobilization and detection of magnetic beads embedded by microbial aggregates but has to be assessed further before proving its usefulness.

\section{Output (microbial responses) and input (environmental and physiological conditions) variables}

Conjugating the interest of the analysis and the ability to perform it using the high-throughput devices, the most obvious output responses to be monitored and included in a biofomics database are arguably biofilm biomass, microbial cells in the biofilm and associated physiological activity, extracellular matrix and overall biofilm structure. Assuming that interlaboratory discrepancies are overcome, all these parameters but for biofilm structure might be quantified using microtiter plates (Table 2). For all microtiter plate-based assays, the final results are based either on color or fluorescence intensity at a certain wavelength, which means that rapid, quantitative analyses are obtained from a single equipment such as an automated multiscan reader. A recent study has concluded that most of these new assays have a broad and robust applicability for many microorganisms (Peeters et al. 2008). Nevertheless, the structure of the biofilm has to be ultimately analyzed by fluorescence microscopy devices such as CSLM and EDIC/EF (Keevil 2003; Merod et al. 2007), which makes it clearly the most time-consuming parameter and the only one to require the application of devices other than the microtiter plates. In this respect, the Calgary device appears to be the frontrunner in terms of high-throughput assessment of structure. This device, coupled with microscopy, might also provide alternatives to assess some of the parameters depicted in Table 2, such as the application of 4',6-diamidino-2-phenylindole (DAPI), 5cyano-2,3-ditolyl tetrazolium chloride (CTC) and SYTO9/propidium iodide for the assessment of total cells, physiologically-active cells and membrane compromised cells, respectively. Unlike using spectrophotometric techniques, assessment by microscopy of these parameters not only provides quantitative data on the total and active number of cells but also provides spatial information. If multispecies biofilms

Table 2 Possible parameters to be included in a biofomics database and suggested high-throughput methods and devices to obtain the data

\begin{tabular}{|c|c|c|c|}
\hline Characteristic & Method & Device & Ref.(s) \\
\hline Biofilm biomass & CV assay & Microtiter plates & (Stepanovic et al. 2000) \\
\hline Microbial cells in the biofilm & Syto9 assay & & (Peeters et al. 2008) \\
\hline \multirow[t]{3}{*}{ Microbial physiological activity } & Fluorescein diacetate assay & & (Honraet et al. 2005; Peeters et al. 2008) \\
\hline & Resazurin assay & & (Pettit et al. 2005) \\
\hline & XTT assay & & (Honraet et al. 2005; Pettit et al. 2005) \\
\hline Biofilm matrix & Dimethyl methylene blue assay & & (Tote et al. 2008) \\
\hline Biofilm structure & High-throughput microscopy & Calgary device & (Harrison et al. 2006) \\
\hline
\end{tabular}


are to be assessed, the relative location of each of the microorganisms within the structure is also important, which adds another parameter to be assessed by microscopy, in this case coupled with fluorescence in situ hybridization (FISH) (Silverman and Kool 2007; Cerqueira et al. 2008).

Hence, microscopy will surely play a key role in the development of a high-throughput methodology in biofilms and it is only timely that high-throughput fluorescence microscopy methods are starting to arise (Pepperkok and Ellenberg 2006). These methods are based on the combination of automated image acquisition, data handling, image analysis and data mining with bioinformatic modeling to provide a rapid flow of work and data.

Because adhesion and biofilm formation are affected by a large range of conditions, it is essential to ensure that every condition apart from the condition that is to be studied remains constant. Relevant conditions include (but are not restricted to) temperature, $\mathrm{pH}$ and $\mathrm{Eh}$, support material, type of liquid medium, concentration of antibiotics or disinfectants, flow rates, microbial species identity, concentration and physiology, among many others (Hall-Stoodley and Stoodley 2005). If, for most of the variables, the application of high-throughput methods in microtiterbased biofilm systems is straightforward, there are a few that might need a little bit more thought during experimental design. Flow rate, for instance, is one of such factors. A possible approach is to use orbital mixers to induce shear stress in the microtiter plates and then apply computational fluid dynamics to simulate flow in each well. This approach allows to determine shear stress at the bottom of the wells as a function of the rotation speed in an orbital mixer (Azevedo et al. 2006b).

A "biofomics" database would hence provide the scientific community with a tool that would allow correlating biofilm formation with environmental, physiological or mutational conditions. Apart from biofilm 3D structure, all data would be quantitative and could be visualized by the users, once the initial conditions were selected. Information on 3D structure would be displayed graphically in similar ways to a localizomics database (Arita et al. 2005; Chen et al. 2007), with the necessary adaptations. Altogether these parameters provide a unique biofilm "signature" that is solely dependent on the input conditions of the system.

\section{Limitations of a "biofomics" database}

Whether "biofomics" is to be undertaken by a research consortium or just one institution, it is imperative that the biofilm growth device, method implementation, and the object of study have been agreed upon before embarking on a large-scale experiment, in order to minimize reproducibility issues. In fact, the complexity of biofilms implies that their characteristics are harder to reproduce than features from a planktonic population, particularly when more than one species is present.

For instance, Hansen et al. (2007) have observed, when forming a two-species biofilm, that the genotype of one of the species tended to suffer adaptive evolution after only 5 days, in order to stabilize interactions and allow the establishment of a spatially structured community. This experiment has been only performed on an Acinetobacter sp. and Pseudomonas putida pair of species, but it is possible, if not likely, that such interactions occur in many other heterotrophic consortia.

Adding the increased variability of multispecies biofilm with the fact that most of the techniques discussed in the previous section are more efficient when applied in monospecies biofilms we suggest that, at least in a first stage, experiments contributing to "biofomics" should start by analyzing single species biofilm formation. Clear candidates for the first experiments are the model organisms for biofilm formation, namely the Gram-negative Pseudomonas aeruginosa, the Gram-positive Staphylococcus aureus and the fungus Candida albicans, but the high-throughput techniques for biofilm studies should allow to rapidly expand the database to other microorganisms.

Even so, the experimental design and the analysis of the results obtained from pure culture studies will certainly require the acquisition and integration of multiple independent datasets to ensure that the data obtained will be a true representation of a microorganism biofilm formation potential under a defined set of conditions. This same strategy has been used to establish many other "omics" datasets (Ge et al. 2003).

\section{Advantages of a "biofomics" approach to biofilms}

Even though there is an obvious gain in terms of the amount and comparability of information acquired in 
Table 3 Fields of research where the creation of a biofomics database would bring a positive impact

\begin{tabular}{|c|c|c|c|}
\hline Field of interest & $\begin{array}{l}\text { Relevant part } \\
\text { of the database }\end{array}$ & Why? & Ref.(s) \\
\hline $\begin{array}{l}\text { Biofilm general } \\
\text { research }\end{array}$ & Whole database & $\begin{array}{l}\text { Provide a framework for biofilm studies to } \\
\text { generate data and interrogate the database }\end{array}$ & - \\
\hline $\begin{array}{l}\text { Water microbial } \\
\text { ecology }\end{array}$ & Water-exposed adhesion & Identify primary colonizers of aquatic biofilms & - \\
\hline $\begin{array}{l}\text { Clinical } \\
\text { microbiology }\end{array}$ & $\begin{array}{l}\text { Pathogens adhesion and } \\
\text { antimicrobial } \\
\text { susceptibility }\end{array}$ & $\begin{array}{l}\text { Rapid determination of relevant clinical features } \\
\text { of microorganisms when adhered } \\
\text { Determination of the minimal inhibitory } \\
\text { concentration }\end{array}$ & - \\
\hline Systems biology & Whole database & $\begin{array}{l}\text { Integrative approaches with other omics } \\
\text { databases. Provide information on the less- } \\
\text { studied microbial subpopulation in a closed } \\
\text { system-the sessile }\end{array}$ & $\begin{array}{l}\text { (Ge et al. 2003; Joyce } \\
\text { and Palsson 2006) }\end{array}$ \\
\hline $\begin{array}{l}\text { Thermodynamics } \\
\text { of adhesion }\end{array}$ & Whole database & $\begin{array}{l}\text { Provide information that might be used to } \\
\text { construct thermodynamic models to predict } \\
\text { adhesion }\end{array}$ & $\begin{array}{l}\text { (Strevett and Chen } \\
\text { 2003) }\end{array}$ \\
\hline $\begin{array}{l}\text { Mathematical } \\
\text { modelling }\end{array}$ & Whole database & $\begin{array}{l}\text { Inform improvements of mathematical } \\
\text { modelling of biofilms using biofilm structure } \\
\text { data }\end{array}$ & $\begin{array}{l}\text { (Xavier and Foster } \\
\text { 2007) }\end{array}$ \\
\hline $\begin{array}{l}\text { Genome-wide } \\
\text { association } \\
\text { mapping }\end{array}$ & Whole database & $\begin{array}{l}\text { Determine causal variants by showing that } \\
\text { particular genotypes are statistically associated } \\
\text { with a phenotypic trait in terms of biofilm } \\
\text { formation }\end{array}$ & $\begin{array}{l}\text { (Falush and Bowden } \\
\text { 2006) }\end{array}$ \\
\hline
\end{tabular}

the field of biofilms, one may always question whether the profits obtained from biofomics are worth the effort.

As described above, the biofomics data should be amenable to be stored in an on-line database as biofilm signatures that are dependent on the input conditions (Table 3). Biofilm signatures could be identified and interrogated by other researchers to confirm biofilm characteristics of the desired system. These signatures would also act as a framework for complex biofilm studies to rely on. For example, biofilms from drinking water distribution systems (DWDS) are usually composed of many species and are formed under a variety of conditions, many of them undefined. Nevertheless, and after the identification of the microorganisms present in the in vivo biofilm, a researcher would be able to obtain from the biofomics database the behaviour of each of those microorganisms in pure culture, under environmental conditions related to those of DWDS (e.g. poor nutrient content and high shear stress). This approach might, for instance, allow to identify the primary biofilm formers (based on the kinetics of adhesion estimated by the number of adhered cells with time) or those microorganisms that hold together the biofilm by producing great amounts of exopolymers in those conditions. Admittedly, part of the overall ecosystem behaviour will only be explained by interspecies community interactions, but if on a second stage the biofomics is expanded in order to obtain multispecies biofilm signatures, even those interactions might be observed in the database. Similarly, researchers would be free to interrogate the database for the signatures that would best serve their purposes for comparison against their own data obtained from in vitro studies obtained with low throughput devices and for other areas of knowledge such as clinical microbiology.

One of the main goals of a biofomics database should nonetheless be the integration with other omics databases. Most omics data are derived from population measurements taken from cells in suspension and are ultimately applied to describe the behaviour of a single cell (cellular model). On the other hand, biofomics provides data that discriminate between two groups of cell populations (planktonic vs. sessile), and characterizes the latter group in terms of physiological activity, matrix production and 
structure (system model). If the experiments are carried out under the same conditions, the conjugation of both types of data is obviously possible, but a biological context as to why this should be done is needed. One of the possibilities would be a systems biology approach at the population-level and not at the single cell-level (Raes and Bork 2008). In fact, and in a true holistic approach, it is not adequate to characterize a single microorganism in a suspension, because even the simplest closed system where omics analyses are possible to be carried out with the present technology is composed of many other cells present in a suspension and in contact with a surface. As under most conditions biofilms are ubiquitous, part of the cell population will certainly be adhered to the surface and contributing to changes in the closed system. Hence, and in the same way as localizomics seeks to identify the subcellular location of all proteins to contribute to a cell model (Joyce and Palsson 2006), biofomics would seek to locate, quantify and characterize the cells in a tightly controlled and closed microbial system and contribute to a system model approach.

Other possible areas of application, which will not be addressed here in detail, are biofilm mathematical modeling, genome-wide association mapping studies and thermodynamics of adhesion.

\section{Concluding remarks}

Recent advances in high-throughput methods to generate and study biofilms have opened the possibility of starting an omics approach to study these complex structures over the next decade. Nevertheless, even in pure culture and tightly controlled experiments a certain degree of stochastic variation is expected to occur, and it is therefore paramount that the biofilm-forming device and the methods for analyses are selected with the purpose of minimizing such variations and the consequent need of taking a higher number of independent samples. Whether such a device and analytical methods are already fully developed, especially for multispecies biofilm formation, is a matter of discussion.

As soon as the devices and methods are agreed upon, the large biofilm data sets obtained should allow the creation of a public "biofomics" database on the internet, where the large amount of information gathered can be freely accessed and correlated according to each researcher needs. The impact of such a database will reach applied areas such as clinical, industrial and environmental microbiology, as well as the systems biology discipline.

\section{References}

Arita M, Robert M, Tomita M (2005) All systems go: launching cell simulation fueled by integrated experimental biology data. Curr Opin Biotechnol 16:344-349

Azevedo NF, Pacheco AP, Keevil CW, Vieira MJ (2006a) Adhesion of water stressed Helicobacter pylori to abiotic surfaces. J Appl Microbiol 101:718-724

Azevedo NF, Pinto AR, Reis NM, Vieira MJ, Keevil CW (2006b) Shear stress, temperature, and inoculation concentration influence the adhesion of water-stressed Helicobacter pylori to stainless steel 304 and polypropylene. Appl Environ Microbiol 72:2936-2941

Baillie GS, Douglas LJ (1998) Effect of growth rate on resistance of Candida albicans biofilms to antifungal agents. Antimicrob Agents Chemother 42:1900-1905

Bakke R, Trulear MG, Robinson JA, Characklis WG (1984) Activity of Pseudomonas aeruginosa in biofilms—-steadystate. Biotechnol Bioeng 26:1418-1424

Battin TJ, Kaplan LA, Newbold JD, Hansen CME (2003) Contributions of microbial biofilms to ecosystem processes in stream mesocosms. Nature 426:439-442

Bochner BR (2003) New technologies to assess genotypephenotype relationships. Nat Rev Genet 4:309-314

Bragança SM, Azevedo NF, Simoes LC, Keevil CW, Vieira MJ (2007) Use of fluorescent in situ hybridisation for the visualisation of Helicobacter pylori in real drinking water biofilms. Water Sci Technol 55:387-393

Burmolle M, Webb JS, Rao D, Hansen LH, Sorensen SJ, Kjelleberg S (2006) Enhanced biofilm formation and increased resistance to antimicrobial agents and bacterial invasion are caused by synergistic interactions in multispecies biofilms. Appl Environ Microbiol 72:3916-3923

Camilli A, Bassler BL (2006) Bacterial small-molecule signaling pathways. Science 311:1113-1116

Ceri H, Olson ME, Stremick C, Read RR, Morck D, Buret A (1999) The calgary biofilm device: new technology for rapid determination of antibiotic susceptibilities of bacterial biofilms. J Clin Microbiol 37:1771-1776

Cerqueira L, Azevedo NF, Almeida C, Jardim T, Keevil CW, Vieira MJ (2008) DNA mimics for the rapid identification of microorganisms by fluorescence in situ hybridization (FISH). Int J Mol Sci 9:1944-1960

Chavant P, Gaillard-Martinie B, Talon R, Hebraud M, Bernardi $\mathrm{T}$ (2007) A new device for rapid evaluation of biofilm formation potential by bacteria. J Microbiol Methods 68:605-612

Chen SC, Zhao T, Gordon GJ, Murphy RF (2007) Automated image analysis of protein localization in budding yeast. Bioinformatics 23:I66-I71

Christensen GD, Simpson WA, Younger JJ, Baddour LM, Barrett FF, Melton DM, Beachey EH (1985) Adherence 
of coagulase-negative staphylococci to plastic tissue culture plates: a quantitative model for the adherence of staphylococci to medical devices. J Clin Microbiol 22:996-1006

Evans RC, Holmes CJ (1987) Effect of vancomycin hydrochloride on Staphylococcus epidermidis biofilm associated with silicone elastomer. Antimicrob Agents Chemother 31:889-894

Falush D, Bowden R (2006) Genome-wide association mapping in bacteria? Trends Microbiol 14:353-355

Feingold EA, Good PJ, Guyer MS, Kamholz S, Liefer L, Wetterstrand K, Collins FS, Gingeras TR, Kampa D, Sekinger EA, Cheng J, Hirsch H, Ghosh S, Zhu Z, Pate S et al (2004) The ENCODE (ENCyclopedia of DNA elements) project. Science 306:636-640

Ge H, Walhout AJM, Vidal M (2003) Integrating 'omic' information: a bridge between genomics and systems biology. Trends Genet 19:551-560

Gilbert P, Allison DG, Evans DJ, Handley PS, Brown MR (1989) Growth rate control of adherent bacterial populations. Appl Environ Microbiol 55:1308-1311

Hall-Stoodley L, Stoodley P (2005) Biofilm formation and dispersal and the transmission of human pathogens. Trends Microbiol 13:7-10

Hansen SK, Rainey PB, Haagensen JAJ, Molin S (2007) Evolution of species interactions in a biofilm community. Nature 445:533-536

Hardie KR, Heurlier K (2008) Establishing bacterial communities by 'word of mouth': LuxS and autoinducer 2 in biofilm development. Nat Rev Microbiol 6:635-643

Harrison JJ, Turner RJ, Ceri H (2005) High-throughput metal susceptibility testing of microbial biofilms. BMC Microbiol 5:53

Harrison JJ, Ceri H, Yerly J, Stremick CA, Hu YP, Martinuzzi R, Turner RJ (2006) The use of microscopy and threedimensional visualization to evaluate the structure of microbial biofilms cultivated in the Calgary Biofilm Device. Biol Proced Online 8:194-215

Harrison JJ, Ceri H, Turner RJ (2007) Multimetal resistance and tolerance in microbial biofilms. Nat Rev Microbiol 5:928-938

Honraet K, Goetghebeur E, Nelis HJ (2005) Comparison of three assays for the quantification of Candida biomass in suspension and CDC reactor grown biofilms. J Microbiol Methods 63:287-295

Joyce AR, Palsson BO (2006) The model organism as a system: integrating 'omics' data sets. Nat Rev Mol Cell Biol $7: 198-210$

Keevil CW (2001) Continuous culture methods to study pathogens in biofilms. Methods Enzymol 334:104-122

Keevil CW (2003) Rapid detection of biofilms and adherent pathogens using scanning confocal laser microscopy and episcopic differential interference contrast microscopy. Water Sci Technol 47:105-116

Kharazmi A, Giwercman B, Hoiby N (1999) Robbins device in biofilm research. Biofilms 310:207-215

Kinniment SL, Wimpenny JWT, Adams D, Marsh PD (1996) The effect of chlorhexidine on defined, mixed culture oral biofilms grown in a novel model system. J Appl Bacteriol $81: 120-125$
Kolter R (2005) Surfacing views of biofilm biology. Trends Microbiol 13:1-2

Kolter R, Greenberg EP (2006) Microbial sciences: the superficial life of microbes. Nature 441:300-302

Liolios K, Tavernarakis N, Hugenholtz P, Kyrpides NC (2006) The genomes on line database (GOLD) v.2: a monitor of genome projects worldwide. Nucleic Acids Res 34:D332D334

McBain AJ, Bartolo RG, Catrenich CE, Charbonneau D, Ledder RG, Gilbert P (2003) Effects of triclosan-containing rinse on the dynamics and antimicrobial susceptibility of in vitro plaque ecosystems. Antimicrob Agents Chemother 47:3531-3538

McLean RJC, Whiteley M, Stickler DJ, Fuqua WC (1997) Evidence of autoinducer activity in naturally occurring biofilms. FEMS Microbiol Lett 154:259-263

Merod RT, Warren JE, McCaslin H, Wuertz S (2007) Toward automated analysis of biofilm architecture: bias caused by extraneous confocal laser scanning microscopy images. Appl Environ Microbiol 73:4922-4930

Nickel JC, Wright JB, Ruseska I, Marrie TJ, Whitfield C, Costerton JW (1985) Antibiotic-resistance of Pseudomonas aeruginosa colonizing a urinary catheter in vitro. Eur J Clin Microbiol Infect Dis 4:213-218

Parsek MR, Greenberg EP (2005) Sociomicrobiology: the connections between quorum sensing and biofilms. Trends Microbiol 13:27-33

Peeters E, Nelis HJ, Coenye T (2008) Comparison of multiple methods for quantification of microbial biofilms grown in microtiter plates. J Microbiol Methods 72:157-165

Pepperkok R, Ellenberg J (2006) Innovation-high-throughput fluorescence microscopy for systems biology. Nat Rev Mol Cell Biol 7:690-696

Pettit RK, Weber CA, Kean MJ, Hoffmann H, Pettit GR, Tan R, Franks KS, Horton ML (2005) Microplate alamar blue assay for Staphylococcus epidermidis biofilm susceptibility testing. Antimicrob Agents Chemother 49:2612-2617

Raes J, Bork P (2008) Molecular eco-systems biology: towards an understanding of community function. Nat Rev Microbiol 6:693-699

Ram RJ, VerBerkmoes NC, Thelen MP, Tyson GW, Baker BJ, Blake RCII, Shah M, Hettich RL, Banfield JF (2005) Community proteomics of a natural microbial biofilm. Science 308:1915-1920

Silverman AP, Kool ET (2007) Oligonucleotide probes for RNA-targeted fluorescence in situ hybridization. Adv Clin Chem 43 43:79-115

Stepanovic S, Vukovic D, Dakic I, Savic B, Svabic-Vlahovic M (2000) A modified microtiter-plate test for quantification of staphylococcal biofilm formation. J Microbiol Methods 40:175-179

Strevett KA, Chen G (2003) Microbial surface thermodynamics and applications. Res Microbiol 154:329-335

Tote K, Vanden Berghe D, Maes L, Cos P (2008) A new colorimetric microtitre model for the detection of Staphylococcus aureus biofilms. Lett Appl Microbiol 46: 249-254

Tringe SG, von Mering C, Kobayashi A, Salamov AA, Chen K, Chang HW, Podar M, Short JM, Mathur EJ, Detter JC, Bork P, Hugenholtz P, Rubin EM (2005) Comparative 
metagenomics of microbial communities. Science 308:554-557

Wilmes P, Remis JP, Hwang M, Auer M, Thelen MP, Banfield JF (2008) Natural acidophilic biofilm communities reflect distinct organismal and functional organization. ISME $\mathbf{J}$
Xavier JB, Foster KR (2007) Cooperation and conflict in microbial biofilms. Proc Natl Acad Sci USA 104: 876-881 